This is a so-called personal version (author's manuscript as accepted for publishing after the review process but prior to final layout and copyediting) of the article.

Vaara, E. On the discursive construction of success/failure in narratives of post-merger integration. Organization Studies, 2002, 23(2), 213-250.

Researchers are kindly asked to use the official publication in references.

\title{
On the Discursive Construction of Success/Failure in Narratives of Post- merger Integration
}

\author{
Eero Vaara \\ Department of International Business, Helsinki School of Economics and Business \\ Administration, Helsinki, Finland
}




\begin{abstract}
This article concentrates on the discursive constmction of success and failure in narratives of post-merger integration. Drawing on extensive interview material from eight Finnish-Swedish mergers and acquisitions, the empirical analysis leads to distinguishing four types of discourse — 'rationalistic', 'cultural', 'role-bound' and 'individualistic' — that narrators employ in recounting their experiences. In particular, the empirical material illustrates how the discursive frameworks enable specific (di.scursive) strategies and moves for (re)framing the success/failure, justification/legitimization of one's own actions, and (re)constniction of responsibility when dealing with socio-psychological pressures associated with success/failtire. The analysis also suggests that, as a result of making use of these discursive strategies and moves, success stories are likely to lead to overly optimistic or, in the case of failure stories, overly pessimistic views on the management's ability to control these change processes. Tliese findings imply that we should take the discursive elements that both constrain our descriptions and explanations seriously, and provide opportunities for more or less intentional (re)interpretations of postmerger integration or other organizational change processes.
\end{abstract}

Descriptors: narrative, merger, acquisition, integration, success, failure 


\section{Introduction}

One of the most significant trends within the social sciences in recent decades has been an increasing interest in language. This is also the case in organization and management studies (Czamiawska 1997a; Grant et al. 1998). The role of narratives, in particular, has been pointed out as central to an understanding of the social construction of organizational phenomena (Czamiawska 1999).

However, organizational research has paid little attention so far to the social construction of success and failure in narratives of organizational change. This is unfortunate, as success and failure stories have a prominent role within and around organizations. In brief, success and failure stories are the basis for learning (Levinthal and March 1993; March and Simon 1993). They also play a crucial roie in institutionalization models, where particular ideas are coined in stories spread within and across organizations, edited and adopted, leading to legitimization and naturalization (Powell and DiMaggio 1991; Sahlin-Andersson 1996). Stories of success and failure are also specifically important sources of empirical information for organizational scholars, although certainly not 'unbiased' ones (Brown and Jones 1998).

Mergers and acquisitions constitute a specifically important area of organizational change. This has also been reflected in an increasing acadetnic interest in these important phenomena. Lately, researchers have concentrated specifically on the post-merger organizational integration processes, which have been seen as crucial in terms of understanding the organizational outcomes of mergers and acquisitions (Haspeslagh and Jemison 1991; Pablo 1994; Gertsen et al. 1998; Larsson and Finkelstein 1999), Like many other areas of organizational change, this literature has, however, been characterized by a manageriaiist orientation, which has meant that little attention has been paid to the processes through which these phenomena are socially constructed. This is ciearly a significant deficiency when trying to understand the social and societal implications of these significant contemporary phenomena.

To partially fill this gap, this article focuses on the discursive construction of success and failure in the case of mergers and acquisitions. More specifically, the article concentrates on narratives of organizational integration following mergers and 
acquisitions. This article reports a study of key actors' accounts of post-merger organizational change in eight historically significant cases of Fitinish-Swedish mergers and acquisitions. The analysis leads to distinguishing four different types of discourse — 'rationalistic', 'cultural', 'role-bound' and 'individualistic' — that the narrators employ in their accounts.

This paper is divided into four sections. The first section provides an overview of research on post-merger organizational integration, highlighting the lack of studies on social constmction processes. The second section introduces narrative analysis as a method that reveals various epistemological layers and interpretations of organizational processes. This section draws from existing cognitive literature on attribution theory to reflect upon the characteristics of success and failure stories. The third section presents the empirical study. The emphasis is on the exemplification of the four discourse types and specific discursive strategies and moves that the narrators make use of when dealing with socio-psychological pressures associated with success/failure. The concluding section concentrates on the implications of the findings for research on mergers and acquisitions and other organizational change processes.

\section{An Overview of the Literature on Organizational Integration Following Mergers and Acquisitions}

Although some earlier researchers have pointed to the significance of the period following the initial merger or acquisition (see, e.g., Kitching 1967), discussion concerning organizational change processes following mergers and acquisitions did not really start before the middle of the 1980s. Researchers discovered at that stage that it is what happens after a merger or an acquisition that is relevant to an understanding of the organizational consequences. From another perspective, the actual problems encountered, especially in related mergers and acquisitions, necessitated the analysis of cumbersome organizational change processes.

This meant that strategic scholars, who, previously, had mostly been concemed with questions such as which acquisition choices are likely to lead to success (Kusewitt 1985; Fowler and Schmidt 1989) or what types of mergers and acquisitions (related or unrelated) lead to better results in terms of synergy or 
financial perfonnance (Lubatkin 1983, 1987; Chatterjee 1986; Porter 1987; Chatterjee and Lubatkin 1990; Seth 1990) also became interested in integration problems (see, e.g., Shrivastava 1986). These strategically oriented studies have concentrated on the questions of how management can bring about expected or other potential synergistic benefits from joining previously separate organizations (Lindgren 1982; Larsson 1990), create value (Haspeslagh and Jemison 1991), transfer capabilities from one organization to another (Laamanen 1997) or enhance leaming (Leroy and Ramanantsoa 1997). These researchers have also listed obstacles to integration from a managerial perspective (Hunt 1990; Haspeslagh and Jemison 1991; Pablo 1994). For example, Haspeslagh and Jemison (1991) illustrate how determinism, value dcstmction and leadership vacuutn are fundamental impediments to integration. A central theme in this stream of research has been that managers should strive for such benefits by carefully examining the opportunities provided by the organizations and then take into account the possible reactions in the organizations.

Other scholars have adopted a more human-resource-oriented perspective by concentrating on organizational responses to mergers and acquisitions. These studies were motivated by a general interest in the human consequences of mergers and acquisitions, and focused on organizational resistance as a fundamental social force causing problems for integration and cooperation. Accordingly, there are many studies that have examined employees' reactions to mergers and acquisitions (Schweiger et al. 1987; Buono and Bowditch 1989; Napier 1989; Cartwright and Cooper 1990; Schweiger and DeNisi 1991; Lohrum 1996). Some have concentrated specifically on the reactions of managers (Cartwright and Cooper 1993; Hambrick and Cannella 1993; Greenwood et al. 1994; Fried et al. 1996). An overall theme in these studies has been that human-resource-related problems usually receive too little attention, or are under-managed, thus seriously hampering organizational integration (Greenwood et al. 1994).

When organizational students discovered 'culture' as a convenient metaphor for the description of various types of organizational phenomena, researchers started to analyze the organizational change processes following mergers and acquisitions from a cultural perspective. Essentially, this has meant elaborating the argument that cultural differences - those in organizational beliefs and values — are major causes 
of organizational problems (see, e.g., Vaara 2000). There are, in fact, many studies that have concentrated on organizational cultural differences (Sales and Mirvis 1984; Buono et al. 1985; Walter 1985; Datta 1991; Chattetjee et al. 1992; Weber and Schweiger 1992; Cartwright and Cooper 1993; Kleppest0 1993; Larsson 1993; Weber et al. 1996). In intemational settings, drawing on literature conceming different national cultural features (Hofstede 1997), researchers have concentrated on national cultural differences (Very et al. 1993; Olie 1994; Calori et al. 1994; Villinger 1996; Weber et al. 1996; Very et al. 1997; Gertsen et al. 1998; Morosini et al. 1998). Some scholars in this field have also focused specifically on acculturation processes (Nahavandi and Malekzadeh 1988; Kleppest0 1993; Elsass and Veiga 1994; Gertsen et al. 1998; Vaara 1999). A general finding has been that from a cultural perspective, organizational integration processes are particularly cumbersome and long-lasting.

Like other literatures on organizational change, the literature on mergers and acquisitions has been dominated by a normative orientation. This has meant that 'success rhetoric' has played a central role in the literature, often leading to a superficial categorization of the cases in question, as successes or failures, and to a search for particular success factors. Unfortunately, this has usually led to the dominance of the managerialist perspective on integration without recognizing other possible perspectives or the ambiguity inherent in these complex social processes.

Traditionally, studies on post-merger or post-acquisition integration processes have conceptualized the change processes as projects where collective management leads the process and personnel constitute the change subjects (Buono and Bowditch 1989; Haspeslagh and Jemison 1991). In fact, conceptualizing post-merger change processes as management-led integration projects (Shrivastava 1986; Nahavandi and Malekzadeh 1988; Larsson 1990; Haspeslagh and Jemison 1991; Pablo 1994) has become a legitimate starting-point and focus for most studies in this field. The rhetoric of 'management of the integration process' has come to dominate the literature, leading, for example, to the identification of different approaches to integration (Nahavandi and Malekzadeh 1988; Napier 1989; Hunt 1990; Larsson 1990; Olie 1990; Haspeslagh and Jemison 1991; Pablo 1994). In practice, these approaches closely parallel various typologies created to distinguish between different kinds of mergers and acquisitions. 
This has meant that the literature has most often reflected the ideal of unified management, with little attention being paid to the intemal divisions among these people. This has been the dominant view, although specific studies have indicated how those planning for the acquisition are often likely to be very committed to the initial justifications and integration ideas, while the others may not be (Duhaime and Schwenk 1985; Jemison and Sitkin 1986; Haunschild et al. 1994) and how decision making in postmerger or post-acquisition integration processes may be chitracterized by various kinds of political features (Hambrick and Cannella 1993; Vaara 2002).

As for personnel, in this literature attention has mostly focused on trating how organizational members are bound to the previously separate cultures in the aftermath of mergers and acquisitions (Buono and Bowditch 1989). Specific studies have shown that this is also the case with managers (Datta 1991; KJeppest0 1993; Cartwright and Cooper 1993; Greenwood et al. 1994; Fried et al. 1996). There are examples, too, of how national backgrounds divide the organizations in the aftermath of intemational mergers and acquisitions (Olie 1994, 1996; Calori, Lubatkin and Very 1994; Viliinger 1996; Weber ct al. 1996; Very et a!. 1997; Gertsen et al. 1998; Morosini et al. 1998). Particular studies have shown that this is also the case with managerial actors (Caiori et al. 1994; Olie 1994; Very et al. 1997).

In brief, analyses examining post-merger organizational integration from perspectives that would challenge the dominant managerialist views, or look at the social construction of these organizational phenomena, are scarce (Risberg 1998; Vaara 1999). Studies that have seriously considered the discursive elements in mergers and acquisitions are almost non-existent. Important exceptions are the study by Hirsch (1986), which examines the metaphors and vocabularies of hostile takeovers, and the analysis by Schneider and Dunbar (1992), which provides a psychoanalytic reading of hostile takeover events. However, in general, the researchers in this area have failed to pay attention to the discursive construction of post-merger organizational integration. 


\section{Towards a Narrative Approach to Success and Failure in Organizationai integration}

The origins of narrative analysis can be traced in literary theory and semiology. However, narratives have been given an increasingly prominent role in social science (Geertz 1973, 1988; Martin 1986; Bmner 1986, 1990; Fisher 1987; Polkinghome 1987; White 1987; McCloskey 1990; Greimas 1991). Lyotard (1979) speaks of the importance of understanding narrative knowledge, which tells about human projects and their consequences as they unfold over time. Fisher (1987) sees all humans essentially as storytellers who have a natural capacity to recognize the coherence and fidelity of the stories they tell and experience. Bmner separates narrative and scientific modes of knowing and goes as far as stating the following (1990: 67): 'The method of negotiating and re-negotiating meanings by the mediation of narrative interpretation is one of the crowning achievements of human development in the ontogenetic, cultural and phylogenetic sense of that expression'.

Although different authors are far from unanimous in their definitions of narratives, most agree upon four things. First, narratives are interpretations of sequential events. This usually requires some type of 'plot' to give meaningful causal stmcture to the sequential events (see, e.g., Bruner 1990). It should be emphasized that while a narrative is composed of a sequence of events that are given meaning by a plot, this plot is not intrinsic to the events, but imposed on them by the author. When telling the account, it is ultimately up to the narrator to create such causal interpretations, the plausibility of which will be judged by the recipients of that account.

Second, narratives assume the intentionality of human action. Narrative analysis has, in fact, often concentrated on the subject positions in the stories. Probably the most famous of these models is Greimas's actantial model (1987), created on the basis of Propp's earlier research (1968), There he distinguishes the roles of 'subject' (main actant), 'object' (the objective of action) and 'adversary' (the opposing forces). Third, narratives are built on different kinds of discourses, which are not infinite in number (Foucault 1973; McKinlay and Starkey 1998). These discourses constmct subject positions and attach identities to the actors. Fourth, narratives and identitybuilding processes are inextricably intertwined. This linkage is 
particularly strong in the autobiography type of narrative, where the author and the central subject are often seen as the same person.

In organization studies, early analyses (Clark 1972; Martin 1982; Martin et al. 1983; Gahmberg 1986) were followed by more wide-spread interest in the 1990s (Boje 1991, 1995; Rappaport 1993; Roe 1994; Hatch 1994; Skoldberg 1994; Corvellec 1995; Czamiawska-Joerges 1995; Czarniawska 1997a, 1997b, 1997c; Gabriel 1995; O'Connor 1995, 1996; Phillips 1995; Bany and Elmes 1997; Brown 1998; Brown and Jones 1998; Peltonen 1998). A central argument in these studies has been that narrative analysis reveals that most organizational phenomena are told, described and redescribed in narrative form. Van Maanen (1988) claims that narratives are not only a legitimate form of explanation, but also the most appropriate vehicle for representing actions and events in organizations. Czarniawska (1997c) states that narratives are the main source of knowledge in organizations. Following Lyotard (1979), she also argues that narrative knowledge is specifically a counterweight to 'scientific knowledge'.'

It should be noted that the epistemological role of narratives is debated in organization studies. Some take a more realist perspective and see narratives as a means for representing organizational change. Others take a radical constmctivist stance and claim that narratives are products of social interaction in particular settings, but not necessarily much more. From the former perspective, it is natural to examine the relationship between narrative representations and 'underlying reality'. On this basis, one can point to issues such as how narratives are plagued by ex-post rationalizations (Brown and Jones 1998). From the latter perspective, it is natural to view narratives as identity-building, because actors make sense of organizational phenomena retrospectively (Weick 1995; Czamiawska 1997a). Some would go as far as stating that narratives ontologically construct personhood (Hyvarinen 1998).

The perspective taken here is to view narratives as an important epistemological layer as such, but also to recognize the linkages with particular historical events. According to this perspective, the practical relevance of the narrative lies not only in the extent to which it corresponds with 'external reality', but rather in its ability to convince the target audience. As Fisher (1987) puts it, communication is tested against the principles of 'probability' and 'fidelity'. 
'Probability' refers to the ability of the narrative to convince the reader as a whole, that is, whether its stmcture and content cohere with other stories told. 'Fidelity', in tum, refers to the individual components of the stories, that is, whether they represent accurate assertions about social reality and thereby constitute good reasons for belief or action.

Central in the narrative approach is thai it highlights the narrator's ability to describe organizational change in different ways. The narrative perspective thus helps to reveal multiple interpretations of organizational change. Many researchers have argued that heterogeneous interpretations are the norm when different narratives of the same processes are compared with each other, although this has not been properly recognized in organizational research (see, e.g.. Brown and Jones 1998). Others have gone further and claimed that it is the role of organizational research to reveal the plurivocality that is easily suffocated under the institutionalized versions of truth (see, e.g., Boje 1995; Kallinikos 1997; Foumier 1998).

It is important to distinguish between differing interpretations resulting from 'real* experiences of particular actors and differing interpretations as constmcted in narratives. While it may often be the case that particular actors, such as managers or employees, often use particular vocabularies when describing their experiences, the narrative approach concentrates on the discursive constmction of different interpretations. This is possible when narratives are understood as identity-building processes where actors are ascribed different identities. From this perspective, the same persons can, for example, describe the processes in different ways when using different discourses. One can also go further and argue that particular discourses force the narrators to use specific perspectives.

Narratives of organizational change are typically based on a description of an original state of affairs and the new transformed state. For example, Greimas (1991) argues that this usually means a transformation from a state of disorder to a new order. In organizational change accounts, this typically means structuring the account into an original state, organizational action and a reversed state (Skoldberg 1994). In academic organizational change literature, especially, there is a tendency to focus on the final state, often conceived as the 'outcome', and then to develop explanations for that outcome. 
In that they are often based on the categorization of the final outcome in terms of its relative success or failure, organizational change narratives are usually success or failure narratives. What is interesting is that the outcomes of complex social change processes - such as post-merger organizational integration - may be conceived in different ways. One can view the changes from the perspective of different social actors. As the previous literature has shown, what is 'synergy' for management may be 'loss of jobs' for employees. There is aiso the temporal aspect. What may appear to be success in the short run may be failure in the longer mn, and vice versa (see, e.g.. Popper 1997).

Similarly, the explanations for the successes and failures may differ significantly. One can, for instance, emphasize the role of management in these processes, as most of the prior literature has done. One can also, however, seek explanations in the actions of other social actors, such as the personnel. Altematively, one can focus on the environment when explaining successes and failures.

Specifically interesting are accounts by actors who have been closely involved in the particular organizational change processes. These accounts are likely to be influenced by particular sociopsychological tendencies. As to the outcome of the change projects, there is usually a strong tendency to depict the outcome as a success rather than a failure (Abrahamson and Park 1994). This tendency is cognitive, in the sense that over-optimism rather than realism can be seen as a sign of mental health (Taylor 1989). In addition, particularly managers in organizations are said to have an optimistic attitude, as they are more used to success than failure in their own careers (Levinthal and March 1993). This tendency may also be political in the sense that there are naturally many reasons as to why particular actors would like to label specific projects as successes rather than failures (Abrahamson and Park 1994). For example, it is important to depict the organization in question as a successful one in the eyes of different stakeholders. It is also very important for one's prestige and career advancement to be associated with successful projects rather than failures.

As to the attribution of success or failure, the previous literature suggests that success and failure stories may differ in this respect from each other. It is well established in cognitive psychology that people attribute success and failure in selfserving ways (Heider 1958; Weiner 1986; Hewstone 1989; Fiske and Taylor 1991). 
This means that success tends to be attributed more to one's own actions, while failure is often attributed to extemal causes. There are also specific studies in organization that highlight the same tendencies (Bettman and Weitz 1983; Staw et al. 1983; Salancik and Meindl 1984; Ford 1985; Clapham and Schwenk 1991; Abrahamson and Park 1994; Gooding and Kinicki 1995; Martinko 1995; Wagner and Gooding 1997; Brown and Jones 1998; Gr0nhaug and Falkenberg 1998; Hofmann and Stetzer 1998). One explanation is that it is simply easier to link success to one's own actions. Another explanation is a need to perceive things in self-serving ways to protect selfesteem. A third explanation is political; there is a need to enhance public esteem. This may be a specifically important issue, especially in the context of significant organizational change processes, the success of which is in many ways tied to the financial rewards, careers and intemal and public esteem of the actors.

We can thus expect that actors' accounts of success and failure of postmerger organizational integration differ from each other in specific settings as to the conception of outcome and explanation of success/failure. Their accounts are not, however, arbitrary constmctions. These narratives are based on specific discourses and discursive practices (see also Foucault 1980), The cmciai point is that different discourses (as discursive frameworks) are iikely to enable different kinds of descriptions of the phenomena at hand (e.g. Heracleaous and Hendry 2000). Thus issues that are taken into consideration and issues that are marginalized depend on the stmctural properties of the discourse. We therefore need to examine what discourses organizational actors employ in their accounts of success and failure.

\section{Research Design and Methodoiogicai issues}

\section{The Empirical Material}

This study is based on extensive interview material gained from key actors involved in eight cases of Finnish-Swedish mergers and acquisitions. The cases summarized in Table 1 are all historically significant ones in the Nordic context. In fact, they represent the first steps towards cross-national integration between Finland and Sweden in the respective industries.

The Finnish Partek Corporation's acquisition of the Swedish Hiab-Foco took place in stages in 1984 and 1985. At that time, it was the largest Finnish acquisition 
ever made in Sweden. A fundamental motive for the acquisition was to develop Partek's existing cargo handling equipment business, and thereby to make the Finnish corporation less dependent on its core business, which was constmction materials. The acquisition was followed by change efforts: re-organizing the acquired company and integrating the marketing channels of Hiab-Foco with those of Nummi, Multilift and Norba (Partek's existing cargo handling units). Integration also led to the creation of a new corporate level inside Partek: Cargotec. Partek has since grown significantly in this sector. Hiab has, however, remained a rather independent company within Cargotec and Partek. This case is generally considered a success account and has received wide attention in the Finnish and Swedish press.

At the time, the merger between Finnish Ovako and Swedish Steel in 1985 was the largest merger that had ever taken place between Finnish and Swedish corporations. A fundamental motive for the merger was that the previous owners wanted to create a new special steel corporation from which their interest could gradually be divested. The merger was followed by significant changes in terms of divestments and new acquisitions. Internally, however, the organization was plagued by continuous argument between different parties. After a market collapse, the owners decided to re-divide the Finnish-Swedish corporation in 1991. This case is seen as the ultimate example of unsuccessful Finnish-Swedish organizational integration.

The Swedish company Asea's acquisition of Finnish Stromberg in 1986 was the largest Swedish acquisition in Finland. A fundamental motive for the acquisition was the development of the Swedish electrical engineering group into a global player. This acquisition was followed by significant changes in the Finnish organization and respective changes in Sweden. Asea merged with the Swiss company Brown Boveri in 1988; gradual integration of the operations of the companies belonging to this group followed. At the Finnish end, this has meant significant investments and growth in the drives and motors sectors, but dis-investments in others. This case is regarded as a success account, and it has received wide recognition in the European press. 
Table 1 Cases in the focus of the analysis

\begin{tabular}{|c|c|c|c|c|}
\hline Merger/acquisition & Industry & $\begin{array}{l}\text { Year of } \\
\text { acquisition/ } \\
\text { merger }\end{array}$ & Focus of analysis & Status at the end of 1997 \\
\hline $\begin{array}{l}\text { Finnish Partek's acquisition of } \\
\text { Swedish Hiab-Foco }\end{array}$ & Cranes & 1984 & $\begin{array}{l}\text { Integration between Partek's } \\
\text { previous cargo handling operations } \\
\text { (Nummi and Multilift) and Hiab- } \\
\text { Foco }\end{array}$ & $\begin{array}{l}\text { Hiab is part of the Cargotec Group of } \\
\text { Partek Corporation }\end{array}$ \\
\hline $\begin{array}{l}\text { Merger between Finnish Ovako } \\
\text { and Swedish SKF Steel }\end{array}$ & Special steel & 1985 & $\begin{array}{l}\text { Integration between the Finnish } \\
\text { organization (former Ovako) and the } \\
\text { Swedish organization (former SKF } \\
\text { Steel) } \\
\end{array}$ & $\begin{array}{l}\text { Owners redivided the company at the } \\
\text { end of 1991; } \\
\text { the remaining parts, Imatra Steel and } \\
\text { Ovako operate independently }\end{array}$ \\
\hline $\begin{array}{l}\text { Swedish Asea's acquisition of } \\
\text { Finnish Strömberg }\end{array}$ & $\begin{array}{l}\text { Electrical } \\
\text { engineering }\end{array}$ & 1986 & $\begin{array}{l}\text { Integration between former } \\
\text { Strömberg's and former Asea's } \\
\text { drives and motors production within } \\
\text { the Asea and ABB group }\end{array}$ & $\begin{array}{l}\text { Asea and Brown Boveri joined forces } \\
\text { in } 1988 \text {; } \\
\text { Strömberg is a part of the global } \\
\text { ABB corporation }\end{array}$ \\
\hline $\begin{array}{l}\text { Finnish Nokia's acquisition of } \\
\text { Swedish Ericsson Information } \\
\text { Systems }\end{array}$ & Computers & 1987 & $\begin{array}{l}\text { Integration between the Finnish } \\
\text { operations (former Nokia IS) and the } \\
\text { Swedish operations (former Ericsson } \\
\text { IS) }\end{array}$ & $\begin{array}{l}\text { Nokia Data was sold to ICL in 1991; } \\
\text { these operations are part of Fujitsu's } \\
\text { global operations }\end{array}$ \\
\hline $\begin{array}{l}\text { Finnish Tietotehdas's acquisition } \\
\text { of Swedish Datema }\end{array}$ & $\begin{array}{l}\text { Computer } \\
\text { services }\end{array}$ & 1987 & $\begin{array}{l}\text { Integration of Swedish Datema's } \\
\text { operations with the Tietotehdas } \\
\text { group }\end{array}$ & $\begin{array}{l}\text { These operations are a part of Tieto } \\
\text { Corporation (Tietotehdas) }\end{array}$ \\
\hline $\begin{array}{l}\text { Finnish Tampella's acquisition of } \\
\text { Swedish Esselte Well }\end{array}$ & Cardboard & 1988 & $\begin{array}{l}\text { Integration between the operations of } \\
\text { former Tampella Packaging and } \\
\text { former Esselte Well within Tampella } \\
\text { and Enso groups }\end{array}$ & $\begin{array}{l}\text { Tampella's cardboard production was } \\
\text { sold to Enso in 1993; } \\
\text { these operations are now part of the } \\
\text { Enso group }\end{array}$ \\
\hline $\begin{array}{l}\text { Finnish Isku's acquisitions of the } \\
\text { Swedish companies Sundo, Facit } \\
\text { and Direktlaminat }\end{array}$ & Furniture & 1993 & $\begin{array}{l}\text { Integration between Isku's business- } \\
\text { to-business furniture production and } \\
\text { the operations of the Swedish units } \\
\text { (Sundo, Facit and Direktlaminat) }\end{array}$ & $\begin{array}{l}\text { The Swedish units are part of Isku } \\
\text { Svenska }\end{array}$ \\
\hline $\begin{array}{l}\text { Merger between Merita and } \\
\text { Nordbanken }\end{array}$ & Banking & 1997 & $\begin{array}{l}\text { Integration between the Finnish and } \\
\text { Swedish operations }\end{array}$ & $\begin{array}{l}\text { Integration is to a large extent in the } \\
\text { planning stage }\end{array}$ \\
\hline
\end{tabular}


The Finnish company Nokia's acquisition of Ericsson Information Systems' data processing division in 1987 was a widely publicized case. A fundamental motive for the acquisition was the desire of the Finnish electronics industry to grow in this lucrative area. The acquisition led to the development of Nokia Data, comprising Nokia Information Systems and Ericsson Information Systems' data division. These integration efforts led to significant changes in the Swedish organization, which made it a famous case in both the Finnish and Swedish media. This attempt to build an integrated Finnish-Swedish corporation ended when Nokia sold this business to the British ICL (owned by the Japanese Fujitsu). This case is generally considered unsuccessful.

The Finnish company Tietotehdas's acquisition of the Swedish Datema in 1987 was motivated by a desire to intemationalize the Finnish computer service group's operations. The acquisition was followed by an intemal crisis and a heavy rationalization programme in the Swedish company in 1987-1990. Later, Datema became a rather independent part of the Finnish Tieto group. This case bears the stigma of ultimate failure and is often referred to by the Finnish and Swedish press as a case of what not to do.

The Finnish conglomerate Tampella's acquisition of the Swedish Esselte Well in 1989 was motivated by the desire to develop Tampella's cardboard production sector into an intemational group. This led to the development of Tampella Packaging. The acquisition was followed by further acquisitions, for example, in Italy. However, specific integration projects, such as the use of fluting (a component in cormgated board production) produced in Heinola, Finland for Esselte Well, did not lead to concrete results in the following years. The situation changed when the Finnish forest sector group Enso acquired this business from Tampella in 1993. This case has not received a great deal of public attention and has a neutral image. In 1993, the Finnish fumiture manufacturer Isku acquired three smaller companies - Sundo, Facit and Direktiaminat - operating in the same sector in Sweden. In addition to being advantageous financial investments, Isku's representatives saw a specific opportunity to sell Finnish-made products through these channels in Sweden. The acquisition has been followed by specific integration efforts, but the Swedish units have continued to 
operate rather independently. This case has not received wide public attention, but is generally regarded as a success.

The largest Finnish-Swedish merger so far, the combination of the Finnish Merita and the Swedish Nordbanken, was announced in 1997. The acquisition has been followed by preliminary decisions as to how to integrate the Finnish and Swedish operations. However, these efforts remain In the planning stage, to a large extent. At the end of 1998, this case, which received a great deal of public attention, was generally regarded as fairly successful.

\section{The Empirical Information-gathering Methods}

The study focuses on material gathered while interviewing 126 people identified as 'key actors', many of whom were interviewed several times, as summarized in Table 2. The first interviews conceming the cases were tnade as early as 1992-1993, but most interviews were conducted between 1994-1997.

The focus was on the people in the upper echelons of hierarchy. Most of the interviewees were board members or other people representing the owners, members of corporate top management, members of division or unit management or middle managers in key positions in the organizations in question. However, the interviewees also included other members of the organizations, such as union representatives and consultants who had played major roles in the post-merger or post-acquisition change processes.-

The interviews concentrated on the success of the organizational integration processes following mergers and acquisitions. The interviewees were selected because they were 'central' actors in these processes. In these interviews, a *story telling' approach was used. In practice, the interviewees were asked to recount their experiences of the integration process in semistructured thematic interviews. This did not, however, mean that, as interviewer, I remained a passive listener. In fact, my interview strategy can be described as 'active' (Holstein and Gubrium 1997) or 'creative' interviewing (Douglas 1985). Characteristic of the approach has been a conscious understanding of the complex relationship between the interviewer and interviewee and the different epistemological layers embedded in the interview. The approach in specific interview situations is close to that described by Douglas (1985: 
25): 'Creative interviewing ... involves the use of many strategies and tactics of interaction, largely based on an understanding of friendly feelings or intimacy, to optimize cooperative, mutual disclosure and a creative search for mutual understanding'.

The specific questions I asked and the themes that were brought up varied from interview to interview as my knowledge of the cases increased and as my empirical research questions evolved. Nevertheless, the following were important themes in these interviews: motives for the merger or acquisition; the course of planning and negotiation processes preceding the actual deals; intended and actual integration strategies; financial performance of the companies and units; changes in the competitive environment and their effect on decisions made; achievement of different types of synergistic benefits; organizational change resistance encountered; cultural differences and confrontation at national, organizational, unit and sub-unit levels; intemal conflicts among key decision-makers between and across the organizations; development of roles and identities at the upper echelons of corporate hierarchy; power relations between key actors; people's personal ambitions and projects; and leaming from one's own and others' experiences.

\section{Table 2 Information on the interviews conducted}

\begin{tabular}{|l|c|c|c|c|}
\hline Merger/acquisition & $\begin{array}{c}\text { Number of } \\
\text { interviewees }\end{array}$ & Finns & $\begin{array}{c}\text { Nationality } \\
\text { Swedes }\end{array}$ & $\begin{array}{c}\text { Number of } \\
\text { interviews }\end{array}$ \\
\hline \hline Finnish Partek's acquisition of Swedish Hiab-Foco & 22 & 13 & 9 & 26 \\
\hline Merger between Finnish Ovako and Swedish SKF Steel & 22 & 13 & 9 & 28 \\
\hline Swedish Asea's acquisition of Finnish Strömberg & 15 & 10 & 5 & 17 \\
\hline $\begin{array}{l}\text { Finnish Nokia's acquisition of Swedish Ericsson } \\
\text { Information Systems }\end{array}$ & 14 & 9 & 5 & 15 \\
\hline $\begin{array}{l}\text { Finnish Tietotehdas's acquisition of Swedish Datema } \\
\text { Finnish Tampella's acquisition of Swedish Esselte Well }\end{array}$ & 10 & 6 & 4 & 11 \\
\hline $\begin{array}{l}\text { Finnish Isku's acquisitions of Swedish companies } \\
\text { Sundo, Facit and Direktlaminat }\end{array}$ & 26 & 13 & 13 & 30 \\
\hline Merger between Merita and Nordbanken & 7 & 5 & 2 & 7 \\
\hline \hline Total & 126 & 75 & 51 & 144 \\
\hline
\end{tabular}


The interviews usually lasted for two or three hours. With a few exceptions, we spoke the mother tongue of the interviewee, Finnish or Swedish. Most of the interviews were tape-recorded. However, in 14 cases, the interviewees preferred that I did not use a tape recorder. All of the tape-recorded interviews were later completely or partly transcribed verbatim. In the case of the interviews that were not taperecorded, I had to rely on notes taken during the interviews.

It should be noted that I also had access to other empirical material, which helped me to put the interviews into proper contexts or understand intertextuality (see Keenoy et al. 1997). This material included documents such as press releases, pieces of news and articles published in journals and magazines, minutes of meetings, different types of plans, many types of financial and technical reports, copies of presentations held, memos and letters. Overall, the documentary material told a great deal about how the cases were generally viewed in different arenas and about the actors' positions in intemal discussions.

\section{The Narrative Analysis}

The starting point for the analysis was to focus on the narratives on organizational decision making in the post-merger context. After an initial search for typical textual characteristics such as themes, key words and metaphors, the analysis proceeded in four stages. At the first stage, I focused on the sequential structure of the narratives. I specifically tried to locate success and failure sequences. This meant that I sought 'mini-narratives' or 'semi-independent' stories that clearly manifested instances of success and failure. Rather than categorizing the texts according to some thematic basis. I found it meaningful to search for different types of narrative sequence that would illustrate different ways of describing and accounting for success and failure experiences. It should be emphasized that the empirical cases as such could not be categorized as successes or failures because different narrators and even the same narrators could describe them as successes or failures depending on the context. Neither could specific narratives be easily categorized as successes or failures, because the stories often included both elements. The accounts could also manifest symagmatic doubling (Greimas 1991: 45): they could present, in succession, first a story of failure and then one of success. In some cases, a story of failure was more an 
account portraying a particularly difficult situation that could be seen as a failure. This would be followed by a process leading to a success.

At this stage, I also proceeded further by distinguishing different segments and syntagms in the specific sequences that I had identified. I could, for example, distinguish syntagms such as qualifying, decisive and glorifying tests (see Greimas 1991) that structured the success accounts. However, when I started to discover the apparent differences in the discourses employed, as will be elaborated below, I did not proceed further in the direction of more fine-grained analysis at the segment or utterance level.

The second stage of the analysis concentrated on the construction of subject positions in these success or failure sequences. I specifically focused on how the decision-makers or managers were described as collectives or individual subjects and how the other actors were portrayed. At this stage, I used Greimas's (1987) ideas as bases for preliminary categorization. In this framework, 'integration success' could be seen as the 'object', the managerial actors as 'subjects', and the other actors working against the managerial intentions as the 'adversaries'. The relationship between the subjects and the 'others' as adversaries was particularly interesting. In brief, it was apparent that the role of the adversary was usually much more central in the failure than success accounts.

At the third stage of the analysis, I discovered that the subject positions, as well as the objective and other actants, were constructed in significantly different ways depending on the larger-scale discursive framework constituting the social setting. This led to a further analysis of the more general constitutive features of the accounts and specific sequences. This meant thai I focused on the analysis and categorization of the various types of discourse found, which eventually led to a typology of four distinctive discourse types: 'rationalistic', 'cultural', 'role-bound' and 'individualistic'. In this inductive process, I also tried to observe critically the linkages to existing dominant discourses in the business press (see Fairclough 1997).

Finally, at the fourth stage, I looked for and categorized specific discursive strategies and moves within and across these four discourses. At this stage, I especially sought examples that highlighted the specific characteristics of these 
discourses and their differences. At this and other stages, I also received help and feedback from specific colleagues who reviewed the empirical material and my categorizations.

\section{Discursive Frameworks, Strategies and Moves in the Construction of Success and Failure Acounts}

The analysis revealed four distinctive discourse types used in these accounts. These discourse types are called here 'rationalistic', 'cultural', 'role-bound' and 'individualistic'. These discourse types assigned different subject positions and identities to the actors in distinctive institutional frameworks. This meant that success/failure was constructed in different ways in the discourses and that the explanations for success and failure were different. The characteristic features of these ideal discourses are summarized in Table 3 below.

'Rationalistic' discourse represented the dominant framework in the descriptions of organizational change in the interviews. An indication of this dominance was that it was clearly the most commonly used.-* This is obviously largely due to the fact that most of the previous literature on organizational change in general, and mergers and acquisitions in particular, is based on this type of discourse. Another indication of the dominance of 'rationalistic' discourse was that the first versions of the accounts offered were usually based on this discursive framework. It was usually only when the interviewees were forced to elaborate their points further and consider the justifications and legitimacy of managerial actions that they reverted to the other discourse types. This was the case, for example, when they had to develop explanations for failures.

Interviewers are unavoidably involved in creating meanings that ostensibly reside with the interviewees (Manning 1987; Silverman 1993; Holsiein and Gubrium 1997). Both parties are active in this construction of the narratives. It is important to note that the relationship between the interviewee and myself, as interviewer, played a significant role. The way in which I constructed the questions and provoked the interviewee obviously had a significant effect on the choice of discourse."* However, the general pattem was that the narrators first seemed to think that 'rationalistic' versions were the 'appropriate' ones. In fact, what usually happened was that the better 
we got to know each other, the more the interviewees were ready to tum to the 'less legitimate' discourses. It is also worth noting that the Finns (my nationality) found it much more natural to revert to the 'cultural' discourse with me than the Swedes.

\section{The Characteristics of Rationalistic Discourse}

'Rationalistic' discourse placed the integration process in an institutional framework of rational decision-making, where particular managers or collective management as change agents led the post-merger integration process. As such, this discourse can be seen as a variant of the general 'rational decision-making' discourse (see, e.g.. Miller et al. 1996) and in particular reflects the most popular models of post-merger organizational integration (see, e.g., Hunt 1990; Haspeslagh and Jemison 1991; Pablo 1994).

Typical of this discourse was that the general need for change or integration was usually not questioned; hence, this discourse clearly coheres with the more general discourse on global capitalism (Fairclough 2000). Instead, 'success' was considered in terms of the traditional performance measures for business enterprises and was rarely problematized. For example, Partek's acquisition of Hiab-Foco or Asea's acquisition of Stromberg could be referred to as success stories, without considering any specific aspects. In their success accounts, it was sufficient for the narrators to point to profitability, strategic position, synergy or lack of organizational resistance. The merger between Ovako and SKF Steel, Tietotehdas's acquisition of Datema and Nokia's acquisition of Ericsson Information Systems could be seen as failures by reference to decreasing profits or to the organizational problems encountered. 
Table 3 Characteristics of four types of discourse in actors' accounts of post-merger organizational integration

\begin{tabular}{|c|c|c|c|c|}
\hline Discourse & $\begin{array}{l}\text { Institutional framework/ } \\
\text { drama setting }\end{array}$ & Characteristic objective & Principal subjects & Principal adversaries \\
\hline Rationalistic & $\begin{array}{l}\text { Rational decision-makers leading a } \\
\text { business enterprise }\end{array}$ & $\begin{array}{l}\text { Success from the perspective of } \\
\text { management (using legitimate } \\
\text { measures of success) }\end{array}$ & $\begin{array}{l}\text { Managerial change agents (usually } \\
\text { as a collective) }\end{array}$ & $\begin{array}{l}\text { 'Personnel' or 'organization' as the } \\
\text { principal (often implicit) adversary } \\
\text { Environment as an 'objectified' } \\
\text { adversary }\end{array}$ \\
\hline Cultural & $\begin{array}{l}\text { Organizational identity in the } \\
\text { framework of previously separate } \\
\text { organizations } \\
\text { National identity in the framework } \\
\text { of national confrontation } \\
\text { Sub-cultural identity }\end{array}$ & $\begin{array}{l}\text { Success from the perspective of } \\
\text { particular organizational side } \\
\text { Success from the perspective of } \\
\text { particular nationality } \\
\text { Success from the perspective of } \\
\text { particular sub-culture or group }\end{array}$ & $\begin{array}{l}\text { Actors representing previously } \\
\text { separate organizations, different } \\
\text { nationalities, sub-cultures or groups }\end{array}$ & $\begin{array}{l}\text { 'The other side' (organization or } \\
\text { nation) as the principal adversary } \\
\text { Conspiring members of 'one's own } \\
\text { side' }\end{array}$ \\
\hline Role-bound & $\begin{array}{l}\text { Role-identity within a corporation } \\
\text { as an institutionalized system }\end{array}$ & $\begin{array}{l}\text { Success from the perspective of } \\
\text { particular area of responsibility } \\
\text { (within the larger context) }\end{array}$ & $\begin{array}{l}\text { Actors representing different areas or } \\
\text { responsibilities }\end{array}$ & $\begin{array}{l}\text { Actors in other roles as principal } \\
\text { adversaries } \\
\text { Conspiring actors not behaving } \\
\text { according to their role-identities }\end{array}$ \\
\hline Individualistic & $\begin{array}{l}\text { Individualistic identity in complex } \\
\text { and fragmented institutional } \\
\text { structures }\end{array}$ & Success/ from the perspective of self & Personified actors & Specific persons as adversaries \\
\hline
\end{tabular}


The subjects of this discourse were the individual managers or collective management making decisions to maximize the integration benefits and minimize the problems caused, for example, by personnel resistance. The 'decision-makers' or 'management' were clearly distinguished from the 'organization' or the 'personnel'. The 'organization' or 'personnel' could be seen as the principle adversary in the Greimasian sen.se, although it was often not explicitly portrayed as such. Success accounts typically pointed to the actions of the collective management or the actions of individual managers. For example, in the case of Asea's acquisition of Stromberg, success was attributed, to a large extent, to the top management's ability to make the decisions needed to achieve synergy benefits. This was described by a Swedish manager, as follows:

'What was important was that we could make those changes, based on careful valuation of potential synergy. ${ }^{\wedge}$

When pointing to the central role of the organization or personnel, the success accounts typically focused on the managerial actors' strategies in winning the support of the personnel or avoiding organizational resistance. For example, in the case of Partek's acquisition of Hiab-Foco, a great deal of the success was attributed to the top management's cautious approach to integration. Narratives described how 'careful decisions', 'taking into consideration the needs of the units' and 'trying to win the support of the personnel' had resulted in 'a positive atmosphere'. An example is the following comment by a central member of Partek's top management.

'What all of this [success] came from was our willingness to go and not to make hasty decisions, but win the support of the organization and develop the foundations for further integration."

Interestingly, in these narratives, the representatives of the acquired unit's management often identified themselves with the collective management, as the following cases highlight:

'Crucial for the success was that the decisions we made and implemented could create a future that would enable positive cooperation between the organizations' [Hiab-Foco and specific parts of Partek]. (Manager of HiabFoco) 
'The success was due to our efforts, which made the personnel [of the acquired company] react positively to changes.' (Manager of Stromberg)

When these accounts focused more on the actions of individual managers, it was typical to attribute success to performances in critical incidents. For example, this meant describing successful strategies in management meetings or successful performance in meetings with the personnel. This was clearly shown in the case of Partek's acquisition of Hiab-Foco.

'I remember when I had to walk in there and confront the personnel [of HiabFoco] for the first time. It was crucial tbat I could give thetn a positive view of the future without limiting our possibilities for rationalization.'

These kinds of examples often involved moves towards 'individualistic' discourse, which, in success accounts, usually cohered well with 'rationalistic' discourse.

In contrast, failure accounts rarely referred directly to the actions of the collective management or specific persons. The narrators found it difficult to acknowledge responsibility without pointing to other factors. Within this discursive framework, failure was typically attributed to 'organizational resistance' or 'environmental changes'. 'Organizational resistance' provided a specifically convenient attribution target for the problems encountered. Although the accounts often left the meaning of organizational resistance unspecified, it is important to note that, in these accounts, the personnel was clearly depicted as the 'adversary'. For example, in the case of the merger hetween Ovako and SKF Steel, a member of the top management stated the following:

'The main cause of failure was clearly organizational resistance. The people in Hellefors or Imatra just could not understand what would have ultimately been in every one's interest.'

Interestingly, some of the narrators could occasionally take up the identity of one of the organizations or personnel, which made it easier to attribute failure to the mistakes of the other members of the management. Nokia's acquisition of Ericsson Information Systems highlighted this tendency, as is evident in this comment by a Finnish manager. 
'You know, this was one man's show [referring to the CEOl. The rest of us had little to do with the central decisions. If I had had the power, I would definitely have followed a different strategy [referring to the radical shutdown decisions made immediately after the acquisition].'

While environmental factors were sometimes mentioned in success accounts, they were given much more emphasis in failure accounts. In fact. the actors could often explain away 'poor profitabihty' by attributing it to the business cycles, while the actual integration efforts could be seen as successful. This was common to interviewees in the merger between Ovako and SKF Steel and in Nokia's acquisition of Ericsson Information Systems' data division. A member of the corporate management of Ovako Steel put it as follows:

'I think people made the mistake of thinking that our strategy [to gradually make the company focus more on the further end of the value chain] had failed when the market collapsed. We didn't make mistakes, it was the market that triggered the crisis [that led to the re-division of the corporation].'

Of the other attribution targets, organizational-level observations were usually objectified by using the terms frequently used in the mergers and acquisitions literature. It is interesting to note that 'strategic fit' played a major role in success accounts, while 'cultural differences' or 'cultural fit' was given a major role in failure accounts. For example, in the case of Asea's acquisition of Stromberg, a Swedish manager described how the combination of the two organizations was a perfect example of strategic fit;

'It was easy to see how there were possibilities for real strategic fit. First, Stromberg's specific products could be sold through ABB's [first Asea's channels]. Second, in other areas we could rationalize operations by combining forces.'

In tum, the CEO of Finnish Tietotehdas explained the failed integration efforts as follows by referring to cultural differences:

'It is clear that cultural differences were the reason for the failure. The management can only do so much in a limited time.' 
These types of references to cultural differences were often bridges or passages where the narrators tumed to 'cultural discourse' in their narratives.^

\section{The Characteristics of Cultural Discourse}

'Cultural' discourse was based on a framework that was very different from the 'rationalistic' one. In contrast to 'rationalistic' discourse, 'cultural discourse' was based on the idea that the actors were not 'neutral' decisionmakers or 'voiceless' members of the organization or personnel, but rather that they were actors identifying with different sides and representing different parties. There were different variants of this discourse, because the narrators could stage the post-merger setting as a confrontation between two organizational camps, two different nationalities or between specific sub-cultures. As such, this discourse was closely associated with the general 'cultural' perspective on organizations (see, e.g., Martin 1992) and refiected the ideas in the 'cultural' literature on mergers and acquisitions (see, e.g., Schneider and Dunbar 1992; Gertsen et al. 1998).

Central in this discourse type was the staging of post-merger decision-making as a confrontation between different cultures, nationalities or sub-cultures, which meant that the conflicting objectives of integration were also usually singled out. Understandably, this allowed radically different interpretations of the success of these processes. For example, in the case of Tampella's acquisition of Esselte Well, the Finnish interviewees referred to the unsuccessful aspect of the integration efforts as follows:

'Although we were otherwise successful, we did not manage to tuake the Swedes [Esselte Well] use our fluting [material used in corrugated board production at the Heinola mills in Finland].' (a Finnish manager of Tampella)

However, at the same time, the Swedish interviewees saw this as a success:

'This period was very successful. What was most important was that we were not forced to make changes that would not have suited our strategy [meaning: using Heinola's fluting].' (a Swedish manager of Esselte Weil) 
Within this framework, the managers identifying with a particular side were the principal actors, while the 'other side' was the obvious 'adversary'. A typical example is provided by a Finnish member of Merita-Nordbanken's management, who pointed out that the first integration decisions had been successful.

'We [managers eoming from Merita] have achieved at least as powerful a position as the Swedes in the new organization structure. Also, we have tried our best ... and succeeded ... to cnstire that future cutbacks will take place on both sides, despite our larger personnel [more employees in specific functions on the Finnish side].'

Interestingly, within this framework, the narrators could contrast corporate level and organization- or unit-specific development. This meant that the narrators reframed (from a 'rationalistic' perspective) unsuccessful corporate-level integration projects as unit-specific survival stories. For example, in the case of the merger between the Finnish Ovako and the Swedish SKF Steel, a representative of a key production unit in Finland (Imatra) reframed the overall failure as follows:

'This was a tough process that ended badly. Luckily we could secure the future of the Imatra steel mill in these negotiations.'

The 'nationalistic' versions of this discourse type were most interesting, as they often placed these organizational change processes in the larger context of national-level considerations or national confrontation, reflecting general nationalist discourse (see, e.g., De Cillia et al. 1999). This nationalism was manifested in interpretations referring to employment or, for example, to exports. For instance, in the case of Asea's acquisition of Stromberg, the outcome could be considered successful because it had contributed to an increase in Finnish exports. This was an aspect emphasized in many interviews with the Finnish managers, for example, as follows:

'This is a success account. You just need to have a look at the exports figures to understand bow successful this acquisition has been. This has actually been the best means for securing steady future employment here' [the main production facilities of the acquired company in Helsinki and Vaasa]. 
Such nationalism, however, was often much stronger in failure accounts. For example, a key manager at the Finnish Isku described their problems in increasing exports via the acquired units in Sweden:

'Once again, this is one of those cases where the Swedes have won. They are not willing or then not capable of seeing our [Finnish] concerns.'

Often, the narrators could link their post-merger experiences with national confrontation in other social domains, such as sports. For example, a key manager of the Finnish Nokia described their failed integration efforts in Sweden as follows:

'It was just like an ice hockey match. This time, however, we tried to make stire that the Swedes would not win.'

Sometimes the narrators clearly identified themselves with particular groups or subcultures, and could thus consider success and failure from these perspectives. For example, especially in the case of the larger organizations, the narrators could adopt the perspective of a particular group and contrast that with others. As a Finnish manager of Stromberg put it:

'We can clearly see that, for engineers, this was a good deal, but not for the many others on the Finnish side who did not have such clear professional competence.'

Within this discursive framework, success accounts typically pointed to one's own side as a collective agency or social movement, as shown in the previous examples. However, this discourse type seemed particularly suitable for narratives of failure. As to one's own actions, this discourse provided an effective means for justifying and legitimizing political actions or organizational resistance. The best example is probably the infamous merger between Ovako and SKF Steel, where the actors on both sides had to account for such behaviour. A central member of the corporate management (a Finn) put it as follows:

'In those critical times, it was of the utmost importance that we [Finns] fought together for the survival of the Finnish special steel production" [meaning the Imatra steel mill, a core production unit in Finland that was facing shutdown]. 
His Swedish colleague pointed to the 'lobbying' campaign of specific Swedish managers:

'Although [otherwise] not successful, we [Swedes] could make sure that no irrational decisions were made concerning the future of Hellefors' [a core production unit in Sweden that was facing shutdown].

In failure accounts, the other side provided a specifically suitable attribution target as the 'adversary'. Obvious examples were the merger between Ovako and SKF Steel, Tietotehdas's acquisition of Datema and Nokia's acquisition of Ericsson Information Systems. In the case of Tietotehdas's acquisition of Datema, the Finns (as expressed by a key Finnish manager in charge of integration efforts in 1988) could blame the Swedes as follows:

"The failure was due to the fact that the Swedes organized a campaign where they made us look like the villains in the company and in the press. This led to a situation where key people left the company [acquired company Datema] and we lost customers.'

In turn, the Swedes saw the Finns as incapable, as described by a Swedish manager:

'What was most difficult was that the Finnish representatives [who came to Sweden] were not experienced enough to handle the situation. They made promises that they eould not keep and were thus ultimately responsible for the chaos.'

Failure accounts drawing on 'cultural discourse' frequently involved conspiracy theories, where members of one's own side could be depicted as 'traitors'. For example, the former CEO of Ovako Steel was described by a Finnish interviewee as conspiring with the Swedes:

'He just went along with the Swedes when it suited his own interests. He did not seem to care much about the future of the Finnish steel production.' 


\section{The Characteristics of Role-bound Discourse}

The third type of discourse is called 'role-bound' here, referring to a setting where the actors were seen as bound by their institutionalized positions in the corporate hierarchy. Although the discourse as such was built on the idea that due to their roles and responsibilities, specific actors strive for different things, these inherently different interests and aspirations were usually contrasted with the overall situation. As a result, the focus was usually more on the 'appropriateness' of the actions taken than on their effectiveness in terms of achieving specific ends (see, e.g.. Match and Olsen 1989). In practice, 'role-bound' discourse often co-existed with 'rationalistic' or 'cultural' discourse and was frequently used by the narrators as a discursive strategy to point to the specifics of particular decision-making settings.

The principal subjects within this framework were the actors holding specific positions. Those holding other positions could be seen as the 'adversaries' in the more politicized versions of this discourse. For example, a key Finnish manager at Nokia described the altermath of their Swedish acquisition as follows: ' ' -

'This was a clear case where you can see that different parties had specific interests. I tried to take the overall corporate perspective, but those in charge of the Finnish and Swedish businesses [and respective units] ciearly sought their own benefits. That ereated some fights, but that's the way it is.'

In the more moralistic versions, it was specifically those who were not behaving according to their ascribed roles, who were seen as the enemies. For instance, a Swedish manager at Datema summarized his experiences as follows:

The problem in these acquisitions is that there are people who are not prepared or willing to behave as they should. They cannot see the bigger picttire and act in a way that is decent.'

Although this kind of role-based staging could be applied to different kinds of role stmctures, the accounts analyzed specifically highlight the institutionalization of ownership, corporate and business-unit levels and respective roles as owners' representatives, corporate managers and business-unit managers. This reflects the institutionalization of the corporate stmcture in general (Berle and Means 1932; 
Chandler 1977; Westley 1990; WiHiamson 1996) and the multinational corporate structure in particular (Ghoshal and Westney 1993).

Success in these narratives was often attributed to the decisions and choices that were made. As in the case of the other discourses, the narrators specifically highlighted their own actions; for example, critical incidents where they had made the right choices. However, this discourse also seemed to be particularly suitable for failure accounts. As to their own actions, the narrators could either limit their own causal role or portray the actions taken as being legitimate and justifiable. It was often the case, in these account, that the narrators portrayed themselves as actors with little control over the overall course of events. For example, members of the corporate management of Ovako Steel (the corporation created as a result of the merger) described their responsibility as follows:

'You see, we [the corporate executive management] had limited control over what was going on within the divisions [business units]. At the same time, it was the board [consisting of the owners' representatives] that did not approve of all our strategies.'

The narrators could also point out that, although they had done precisely what was appropriate, it had had little weight in the overall situation. Interestingly, the rolebound discourse was often used to justify or legitimize inaction. For example, a manager of the Finnish Tampella described his actions when trying to increase Finnish exports to the acquired Swedish Esselte Well (that did not lead to concrete results):

'I think that we did the decent thing. We did not enter this intemal politicking but only calmly and rationally presented our views to top management.'

As for the others, it was rather easy to point to the detailed mistakes made by other actors, or to the illegitimacy of their actions. For example, in the case of Ovako Steel, the owners (as expressed by a representative of the Swedish owners) blamed the corporate management:

'It is clear that it was ultimately the top management and specifically the CEO who should have niade the needed decisions and implemented the changes. 
You know, we [the hoard] got a highly distorted picture of what was going on.'

The corporate management blamed the heads of units, or managers of particular companies (in the words of the CEO):

'I would like to stress ... that the people in Imatra and Hellefors [referring to the men in charge of these units] should have done a better job. They should have stuck to our decisions instead of doing all kinds of other things behind my back.'

In turn, business-unit managers (in the words here of a Finnish manager) often blamed the other side or the corporate management:

'I do not understand why the corporate management could not make clearer decisions conceming our responsibilities [referring to the divisions of product responsibilities between Imatra in Finland and Hellefors in Sweden]. They should have said that this is it, and acted in a consistent manner.'

When the narrators pointed to the 'illegitimacy' of the actions taken, the accounts often became moralistic. For example, the Finns, in the case of Isku's acquisitions in Sweden, referred to the 'illegitimate' behaviour of the Swedish managers (in the words of a Finnish manager holding a key position):

'They simply did not do the right thing. They should have understood their position as links between the parent company [Isku] and their own units. Taking this narrow Swedish perspective was not acceptable.'

Many of the failure accounts drawing on the 'role-bound' discourse included conspiracy-theory elements. Typical of these narratives was that people were singled out for intentionally behaving in a way that was inappropriate to their positions (see the reference to 'behind my back' above).

\section{The Characteristics of Individualistic Discourse}

The fourth type of discourse is called 'individualistic' here. Within this discursive framework, social identification was less unilateral, but based on more complex and 
fragmented structures. In particular, there was reflection based on individuality and personal characteristics. In this sense, this discourse was the 'postmodern' alternative to the other discourses where the actors were seen as being more tied to their social positions (for a discussion on postmodern identity, see Czamiawska 1997a).

In these accounts, the actors usually provided highly personified stories of the post-merger decision-making processes. At times, the accounts drawing on this discourse were actually individual autobiographies in this particular context. This meant that the objectives of post-merger integration were also framed in individual terms. The narrators could thus point to the effects from the perspective of specific people, including themselves. Often the actors in these accounts contrasted more general benefits with the particular interests of specific individuals, thus combining, for example, 'rationalistic' and 'individualistic' discourses.

The subjects were thus individual actors with distinctive identities. Other individuals could be seen, respectively, as the 'adversaries', although combinations of different discursive frames couid also lead, for example, to constructing the 'other side' as the adversary against which one was fighting.

In success accounts, this discourse provided the means to give or take creditfor the positive outcomes. This often meant making heros of particular actors. A typical example was a Swedish manager's description of the performance of the CEO of Asea in the case of Asea's acquisition of Stromberg.

'He worked very hard to achieve this result. The success was due to his exceptional ability to combine rational thinking and to persuade others to work together. He was the man that made all this happen.'

Credit taking was typically manifested as follows (as expressed by a key Finnish manager in the case of the Finnish Nokia's acquisitions in Sweden):

'It was a difficult task to carry out [the integration of the Swedish units]. It often felt like a mission impossible. But I said to myself, now you have to go ahead and use all the experience that you have and simply make it work. It was a good thing that I was used to difficult decision-making situations, hecause without such a background it would have been impossible,' 
In failure accounts, this discouree provided a means for limiting one's own responsibility by pointing to the social and other constraints imposed on one's actions. For example, a manager of Tietotehdas in charge of the integration efforts describes his own actions in the change processes following the acquisition of Datema, as follows:

'If anything, I was a small player in this project. I was fonnally in charge, but my superiors in Finland had the final say on everything. The Swedes were used to their own decision-making practices, and my ability to make the message clear was limited. I had a specific background [primarily finance and general management] and could not go into the technical discussions. On my part, given this situation, I think that I did the best I could.'

This discourse provided a powerful means for attributing blame in the form of scapegoating or culpriting (see also Brown and Jones 2000). This meant that particular actors could be framed, for example, as incapable or for making mistakes (e.g. in a 'rationalistic' frame) or behaving in an 'illegitimate' way (when compared with 'rationalistic' or 'role-bound' discourse). An example of pointing to mistakes is provided by a Swedish manager in describing the Finnish Isku's acquisitions in Sweden.

'You know, these people were not capable of handling the situation. Especially $\mathrm{X}$ should have understood that you have to make quick decisions, otherwise you lose the momentum. He should have made the plans clear in our meetings and should have visited us [the Swedish unit]. You know in Sweden, it is not OK for the man in charge not to show his face."

Framing a particular person's actions as 'illegitimate', in tum, often meant reference to political behaviour that served the interests only of that person. These individuals were described as striving primarily for the promotion of their own careers, salary or public esteem. For example, in the case of Nokia's acquisition of Ericsson Information Systems' data division, the local Swedish management was blamed (by a Finnish manager) in the following way: 
'I think their behaviour [resistance to changes] was logical. They were afraid of losing their jobs or status as heads of this and that. Instead, they now had to work under Finnish leadership.'

This was particularly well illustrated in narratives of the merger between Ovako and SKF Steel, where the CEO was harshly blamed (by a representative of the Swedish owners) for the ultimate failure:

'One cannot but conclude that he is the guilty party. I think that, for him, it was most important to be able to show off how big a corporation he was building, with huge investments. When the problems started to show, he left the company. I think that he was only interested in his own career.'^

\section{Examples of Multiple Legitimization}

It should be emphasized that, in practice, to create convincing accounts, many of the most detailed accounts combined elements of the different discourses (see, e.g.. Fisher 1987). This was especially the case in failure accounts, where the narrators wanted to make particular points conceming the legitimacy or illegitimacy of specific actions or to make strong claims conceming the responsibility of particular actors.

When searching for legitimacy and justification for one's own actions, the narrators could make use of several discourses, as illustrated by a Swedish manager of Ovako Steel in justifying his intemal political campaigning. In the example below, he blends elements of all four discourses.

'What I did was the right thing to do from the perspective of trying to preserve the value of the company in crisis. Clearly, the situation required committed actions. Naturally, being a Swede and officially responsible for that part of our operations, I was forced to consider mainly the situation at Hellefors [a Swedish production unit].'

Combining elements of the different discourses was also common in accounts where the narrators blamed specific parties or actors. This is well exemplified by a Swedish manager drawing especially on 'cultural', 'rolebound' and 'individualistic' discourses 
when pointing to the responsibility of the Finnish corporate management in not being able to create synergy after Isku's acquisitions in Sweden.

'They, and especially $\mathrm{X}$, should have taken their role more seriously. They should have stopped thinking like Finns and should have come here and learned to know our strengths better. Maybe it is a cultural thing, but I also think that they, as individuals, are not simply experienced or skillful enough.'

Especially in conspiracy theories, the narrators often combined different discourses, such as in the following cases where elements of 'cultural', 'role-bound' and 'individualistic' discourses were skillfully blended to single out the conspiring culprits.

'It is specifically $\mathrm{X}, \mathrm{Y}$, and $\mathrm{Z}$ who are to blame [for the failure]. They represented the Swedish Mafia in the corporation, wbo primarily looked out for their own interests. They eould mislead the top management [corporate executive management]. In practice, they were our main enemies in this issue' [debate conceming investments in the Finnish production unit], (a Finnish manager of Ovako Steel)

'I think that the men in charge in Finland [points later to specific members of the corporate management of Nokia] should have taken a more neutral stand here and paid a little more attention to our needs. Instead, they seemed to be only proud to show us that they no longer suffered from the "little brother complex'" [that is typical of Finns in their relationship with Swedes; in Swedish: lillebrorsyndrom]. (a Swedish manager of Ericsson Information Systems)

By drawing on several discourses, the narrators could often create particularly powerful accounts when the different elements made up a 'rich' and 'convincing' story (see also Fisher 1987: Czamiawska 1997a). However, sometimes, combinations of several elements also led to a lack of overall coherence, which could weaken the mini-narrative or account as a whole (see, e.g.. Fisher 1987). 


\section{Conclusion '}

The main findings of this analysis are three-fold. First, by identifying four discourse types, the analysis reveals discursive frameworks that provide opportunities for different (re)constructions and (re)interpretations of postmerger integration processes. Second, in the context of these discourses, this study specifically illustrates discursive strategies and moves that the narrators make use of when dealing with sociopsychological pressures associated with success/failure. Third, as an implication of the use of these strategies and moves, the analysis suggests that success stories are likely to lead to overly optimistic, and failure narratives to overly pessimistic views on the management's ability to control these change processes.

This study has identified four specific discourse types — 'rationalistic', 'cultural', 'role-bound' and 'individualistic' — that the narrators employed when (re)constmcting success/failure in the context of post-merger integration. By so doing, this study reveals and exemplifies discursive elements through which these phenomena are socially constructed and through which managerial actions are legitimized and naturalized. This study thus adds to the scarce studies examining the discursive construction of organizational change in general (Czamiawska 1997a) and mergers and acquisitions in particular (Hirsch 1986; Schneider and Dunbar 1992).

These discourses were based on different ways of constructing organizational and managerial identities and imposed different types of subject positions upon the central actors. This meant that when the narrators (re)described the post-merger integration processes, they were at the same time (re)constructing their own and other's identities and subject positions and thus were defining what was important and legitimate in this context. In many ways, the narrators could make use of these different discourses when they wished to frame the post-merger integration processes in specific ways. However, it should be noted that these discourses also constrained these (re)constructions and (re)descriptions.

The 'rationalistic' discourse proved to be the dominant discourse of these narratives, while the other discourses — 'cultural', 'role-bound' and 'individualistic' — could be seen as altemative discursive frameworks. This is not an unexpected finding in the sense that the existing literature on mergers and acquisitions is largely 
dominated by 'rationalistic' discourse. It is, however, important to pay attention to two specific features of 'rationalistic' discourse. First, while 'cultural', 'role-bound' and 'individualistic' discourses could problematize and relativize success and failure, as the managerialist orientation was prevalent, 'rationalistic' discourse offered few possibilities for plurivocal or critical interpretations. Second, while the 'cultural' discourse illustrated confrontation between different camps, the 'rolebound' discourse highlighted the structural conflicts of interest between the decision-makers and the 'individualistic' discourse manifested individuallevel power games, within the 'rationalistic' discourse, there was a specific tendency to hide intemal politics among the decision-makers.

Although prior studies on causal attributions in the context of organizational change have provided clear evidence of specific attributional tendencies, these findings have been far from subtle, because they have not been linked with different discursive frameworks (see, e.g., Abrahamson and Park 1994; Gooding and Kinicki 1995; Martinko 1995; Wagner and Gooding 1997; Brown and Jones 1998). The analysis adds to this literature by illustrating how the different discursive frameworks enable specific (discursive) strategies and moves for (re)framing the success/failure, overall justification/legitimization of one's own actions and (re)constnicting responsibility to deal with the complex socio-psychological pressures associated with success/failure.

First, the narrators could (re)frame success/failure so that what had previously been considered as failures could be re-described as successes (or vice versa). For example, by reverting to 'cultural discourses' the actors could reframe, in tnany cases, a less successful corporate development story as a unit level or nationally important survival narrative. By reverting to 'role-bound' discourses, the narrators could relativize success/failure even further by a juxtapositioning unit, role or ftmctionspecific considerations.

Second, the narrators, in general, used the narratives to justify and legitimize their own actions in this context. The need for this was obviously far greater in failure, than in success accounts. For this purpose, they could move to specific discourses; for example, from 'rationalistic' to 'cultural'. This was a means of finding legitimacy for political behaviour that sought the benefit of a particular side or unit rather than of the 
whole, as in the 'rationalistic' case. They could also point to the 'role-bound' nature of decision-making and thus justify, for example, personal or social inaction.

Third, and most interestingly, the narrators (re)constnicted responsibility through specific discursive strategies and moves. As could be expected, the narrators frequently emphasized their own responsibility in success accounts and the role of others in failures. This analysis particularly points to the central role of the 'adversary', both in credit-taking and blame-avoiding accounts; a discursive feature that has received little attention in prior research on attributions in organizations. The 'adversary' was needed lor the heroification or glorification of one's own actions in success accounts but it was even more central in the failure accounts where the narrators wished to avoid responsibility.

In brief, in success accounts, the narrators tended to emphasize their own role or causal position by pointing to their own actions or to those of the collective management. 'Rationalistic' discourse was an effective means for taking credit as a collective (of which one was a part). 'Individualistic' discourse was a very effective choice for heroifying or glorifying one's own actions or those of other key individuals. Often, in the actual accounts, these discourses were, in fact, blended.

In the failure accounts, the narrators could exploit two strategies when avoiding blame. First, they could try to limit one's own responsibility. This couid be done, for example, by (re)framing oneself as being not too central a decision-maker. Altematively, the narrators could revert to the 'role-bound' discourse, which, as such, can be seen as a particularly interesting blame-avoidance strategy. Specifically interesting is that, in this discourse, the key decision-makers could be portrayed as relatively 'powerless' actors — in striking contrast to the 'rationalistic' or 'individualistic' discourses.

Second, the narrators could attach blame to others by using different strategies such as 'scapegoating' or 'conspiracy-theory' building. In the case of 'scapegoating', the narrators could either point to the mistakes that particular actors had made, or then frame the actions as iflegitimate. Ciaims of illegitimacy, in particular, often required a careful description and framing of the setting, so that the legitimate and illegitimate actions could be contrasted and singled out. The conspiracy theories were the most 
interesting of the blame-attachment strategies, as they required particularly clear 'evidence' of illegitimacy, which usually entailed the need to elaborate and (re)describe the setting in a detailed way and, consequently, the need to combine elements of the different discourses.

As a result of making use of these discursive strategies and moves, success accounts were often rather straightforward narratives highlighting particular actions performed by collective management as causes of success, while failure accounts were usually more complex narratives. This can be taken as further evidence of failure accounts being more detailed descriptions than success accounts (see also Brown 1998). However, one can go further and argue that, while success narratives often manifested a linear logic of successive temporal events, the failure stories were characterized by more complex logics, as these accounts could include many kinds of interconnected explanatory elements (see also Burrell 1992).

It is important to understand that by emphasizing the actions of the top management as causes of success, the success accounts gave a more omnipotent view of the management agency. This was especially the case with 'rationalistic' discourse that overall tended to pay little attention to the intemal divisions within the management or the politics between the central decision-makers. The failure account, on the other hand, gave a much more deterministic view of these processes, by placing more emphasis on the role of the other actors as adversaries and by pointing to the limits to particular managers' ability to control these processes. These are significant findings, which indicate that success narratives may often lead to overly optimistic views on the managers' ability to lead organizational change processes, while failure accounts may create overly pessimistic ideas.

The broader significance of these findings becomes clear when one considers the central role of 'rationalistic' success stories in the business press. Their dominant role can, in fact, partially explain the often experienced illusion of control, when planning for mergers and acquisitions (Duhaime and Schwenk 1985; Jemison and Sitkin 1986). This dominance can also help us to understand the current 'merger mania' - the increasing popularity of mergers and acquisitions, despite high failure rates. 
This study has been exploratory in nature. There are several issues that warrant further research. First, as this study has concentrated on the decision- makers' own narratives, it would be interesting to contrast these with accounts produced by others, such as employees and other stakeholders. One could, for example, itnagine that other actors would be prone to use other discursive frameworks and to use different attributional strategies, because they are not so directly involved with the responsibility for success/ failure. Second, it would also be tneaningful to examine the social constmction of mergers and acquisitions in the media, for example, by adopting methods of critical discourse analysis (see, e.g., Fairclough 1997; Tienari et al. 1999; Mazza and Alvarez 2000). Among other things, this could provide more information conceming the relative dominance of 'rationalistic' discourse.

Third, it would be interesting to study the stmctural characteristics of narratives more thoroughly. This study clearly indicates that success stories are usually more straightforward than failure narratives. The extent to which this is a manifestation of failure narratives being built on more complex logics is worth investigation (see, e.g., Burrell 1998). Fourth, it would also be interesting to examine the relative power of different accounts in specific settings. One idea arising from this empirical material is that those accounts that draw on multiple discourses are the ones that can most easily become institutionalized and legitimated versions, both within specific organizations and in the media.

Fifth, while this study has pointed to the interesting characteristics of specific blame- attachment strategies, such as 'scapegoating' and 'conspiracytheory building', their use is certainly an important topic for further research (see also Brown and Jones 1998). It would be very interesting to specify the use of these strategies within different discursive frameworks, for example, by specific methods of conversation analysis.

In conclusion, this study illustrates the socially constmcted nature of success/ failure, an aspect that is often not taken seriously in managerialistically oriented literatures on organizational change. Clearly, we should be aware of the discursive elements that both constrain our descriptions and explanations and provide opportunities for more or less intentional (re)inlerpretations. This is a methodological challenge for (re)constructing historical narratives of organizational change processes, 
but it is also a broader epistemological issue when considering the role of success stories in the business literature.

\section{Notes}

1. While arguing for the importance of narrative knowledge, Jeffcutt (1994), Phillips (1995) and Watson (2000), however, state that the division between narrative fiction and traditional forms of organizational analysis is overdrawn.

2. 11 is noteworthy that the interviewees included more Finns than Swedes. The primary reason for this was that there were more Finns in the upper echelons of the post-merger organization, as, in most cases, the Finns were the acquiring party. The exception is Asea's acquisition of Stromberg, where, due to the large size of the Asea organization, it was meaningful to focus on Stromberg and pay less attention to the various businesses of Asea, many of which had few connections witfi the operations of Stromberg.

3. Although any measures concerning the relative dominance of any discourse type should be viewed with a critical eye, a crude sign of this dominance was that approximately 55 percent of the textual material analyzed could be categorized as 'rationalistic' while the 'cultural', 'role-bound' and 'individualistic' discourses corresponded to 25, 10 and 10 percent, respectively. These kinds of categorizations are, however, problematic, because particular pieces of text often include or manifest several discourse types. These crude figures are based on a categorization based on the 'strongest' discourse in each piece of text.

4. For example, the nature and sequencing of the questions could influence the choice of discourse and subsequent discursive moves. However, the 'story-tell ing' approach, as such, meant that the interviewees as narrators had significant freedom when accounting for their experiences. It should also be emphasized that the questions that were asked varied signicantly in terms of their content and sequencing from interview to interview, and they did not as such create any overall pattem.

5. All these quotes are translations from Finnish or Swedish into English.

6. In 'rationalistic' discourse, cultural differences were objectified features of the organizations. In 'cultural' discourse, cultural differences were the basis for the identification of the actors.

7. Attribution of failure to persons who left the companies in crises were particularly common. 


\section{References}

Abrahamson, Eric, and Choelsoon Park 1994 'Concealment of negative organizational outcomes: An agency theory perspective'. Academy of Management Journal 37: 13021334.

Barry, David, and Michael Elmes 1997 'Strategy retold: Toward a narrative view of strategic discourse'. Academy of Management Review 2: 429-452.

Berle, Adolf A., and G. C. Means 1932 The modem corporation and private property. New York: Commerce Clearing House.

Bettman, James R., and Barton A. Weitz 1983 'Attributions in the boardroom". Administrative Science Quarterly 28: 165-183,

Boje, David M. 1991 'The storytelling organization: A study of account performance in an office-supply firm'. Administrative Science Quarterly 36: 106-126.

Boje. David M. 1995 'Accounts of the storytelling organization: A postmodern analysis of Disney as "Tamara-Laad" \Academy of Management Journal 38: 9971035.

Brown. Andrew D. 1998 'Narrative, politics and legitimacy in an IT implementation'. Journal of Management Studies 35: 35-58.

Brown, Andrew D., and Matthew R. Jones 1998 'Doomed to failure: Narratives of inevitability and conspiracy in a failed IS project'. Organization Studies 19/1:73-88.

Brown, Andrew D., and Matthew R. Jones 2000 'Honourable members and dishonourable deeds: Sensemaking. impression management and legitimation in the '"Arms of Iraq Affair'". Human Relations 53: 655-690.

Bruner, Jerome 1986 Actual minds, possible worlds. Cambridge, MA: Harvard University Press.

Bruner. Jerome 1990 Acts of meaning. Cambridge, MA: Harvard University Press. 
Buono, Anthony R. and James L. Bowditch 1989 The human side of mergers and acquisitions. Managing collisions between people, cultures, and organizations. San Francisco, CA: Jossey-Bass.

Buono, Anthony F., James L. Bowditch, and J. W. Lewis 1985 'When cultures collide: The anatomy of a merger'. Human Relations 38: 477-500.

Burrell, Gibson 1992 'Back to the future. Time and organization" in Rethinking organization: New directions in organization theory and analysis. M. Reed and M. Hughes (eds.), * 165-183. London: Sage.

Burrell, Gibson 1998 "Linearity, control and death" In Discourse + organization. D. Grant, T. Keenoy and C. Oswick (eds.), 134-151. London: Sage.

Calori, Roland, Michael Lubatkin, and Philippe Very 1994 'Control mechanisms in cross-border acquisitions: An intemational comparison'. Organization Studies 15/3: 361-379.

Cartwright, Susan, and Cary L. Cooper 1990 'The impact of mergers and acquisitions on people at work: Existing research and issues". British Journal of Management I: 65-76.

Cartwright, Susan, and Cary L. Cooper 1993 'The psychologicaJ impact of merger and acquisition on the individual: A study ot building society managers". Human Relations 46: 327-347.

Chandler. Alfred D. 1977 The visible hand. Cambridge, MA: Harvard University Press.

Chatterjee, Sayan 1986 'Types of synergy and economic value: The impact of acquisitions on merging and rival firms'. Strategic Management Journal 7: 119-139.

Chatterjee. Sayan, and Michael Lubatkin 1990 "Corporate mergers, stockholder diversification, and changes in systematic risk'. Strategic Management Journal II: 255-268. 
Chatterjee. Sayan, Michael Lubatkin. David M, Schweiger, and Yakoov Weber 1992 'Cultural differences and shareholder value in related mergers: Linking equity and human capital". Strategic Management Journal 13: 319-334.

Clapham, Stephen E., ;ind Charles R. Schwenk 1991 "Self-serving attributions, managerial cognition, and company performance". Strategic Management Journal 12: 219-229.

Ctark. Burton R. 1972 "The organizational saga in higher education'. Administrative Science Quarterly 17: 178-184.

Corvellec, Hervé 1995 Accounts of achievements: Narrative features of organizational performance. Lund: Lund University Press.

Czamiawska-Joerges, Barbara 1995 'Narration or science? Collapsing the division in organization studies". Organization 2: 11-33.

Czamiawska, Barbara 1997a Narrating the organization. Chicago: University of Chicago Press

Czamiawska. Barbara 1997b 'A narrative approach in organizti tion studies'. Thousand Oaks: Sage.

Czamiawska. Barbara 1997c 'A four-times told tale: Combining narrative and scientific knowledge in organization studies'. Organization 4: 7-30.

Czamiawska, Barbara 1999 Writing management: Organization theory as a literary genre. Oxford: Oxford University Press,

Datta, Deepak K. 1991 'Organizational fit and acquisition performance: Effects of post-acquisition integration'. Strategic Management Journal 12: 281-297.

De Cillia, Rudolf, Martin Reisigl, and Ruth Wodak 1999 'The discursive construction of national identities'. Discourse and $\bullet$ Society 10: 149-173.

Douglas, Jack D. 1985 Creative interviewing. Beverly Hills: Sage. 
Duhaime. Irene M., and Charles R. Schwenk 1985 'Conjectures on cognitive simplification in acquisition and divestmeat decision making'. Acaiiemj' of Management Review 10: 287-295.

Elsass, Priscilla M., and John F. Veiga 1994 'Acculturation in acquired organizations: A force-field perspective'. Human Relations 47: 431^53.

Fairclough, Norman 1997 Critical discourse analysis: The critical study of language. London: Longman.

Fairclough, Nonnan 2000 'Guest Editorial: Language and neoliberalism'. Discourse and Society 11: 147-147.

Fisher, Walter 1987 Human communication as narration: Toward a philosophy of reason, value, and action. Columbia: University of South Carolina Press.

Fiske, Susan T., and Shelley E. Taylor 1991 Social cognition, 2nd. Ed. New York: Random House.

Ford, Jeffrey D. 1985 'The effects of causal attributions on decision-makers' responses to performance downturns'. Academy of Management Review 10: 770- 786.

Foucault, Michel 1973 The order of things: "Die archaeology of human sciences. New York: Vintage Books.

Foucault, Michel 1980 Power/knowledge, edited by C. Gordon. Brighton: Harvester Press.

Foumier, Valerie 1998 'Stories of development and exploitation: Militant voices in an enterprise culture'. Organization 5: 55-80.

Fowler, Karen. L., and Dennis R. Schmidt 1989 'Determinants of tender offer postacquisition financial performance'. Strategic Management Journal 10: 339-350.

Fried, Yitzhak, Robert B. Tiegs, Thomas J. Naughton, and Blake E. Ashforth 1996 'Managers' reactions to a corporate acquisition: A test of an integrative model', Journal of Organizational Behavior 17: 401^27. 
Gabriel, Yiannis 1995 "Hie unmanaged organization: Accounts, fantasies and subjectivity'. Organization Studies 16/3: 477-501.

Gahmberg, Henrik 1986 Symbols and values of strategic - A semiotic approach. Helsinki: Helsinki School of Economics.

Geertz, Clifford 1973 77ie interpretation of cultures. New York: Basic Books.

Geertz, Clifford 1988 Work and lives: The anthropologist as author. Stanford: Stanford University Press.

Gertsen, Martine, Anne-Marie Söderberg, and Jens Erik Torp 1998 Cultural dimensions of intemational mergers and acquisitions. Berlin: Walter de Gruyter.

Ghoshal, Sumatra, and D. Eleanor Westney 1993 Organization theory and the multinational corporation. New York: St. Martin's Press.

Gooding, Richard Z., and Angelo J. Kinicki 1995 'Interpreting event causes: The complementary role of categorization and attribution processes'. Journal of Management Studies 32: 1-22.

Grant, David, Tom Keenoy. and Cliff Oswick 1998 "Introduction: Organizational discourse: Of diversity, dichotomy and multi-disciplinarity' in Discourse + organization. D. Grant, T. Keenoy and C. Oswick (eds.). 1-13. London: Sage.

Greenwood, Royston, C. R. Hinings, and John Brown 1994 'Merging professional service firms'. Organization Science 5: 239-257.

Greimas, Algirdas Julien 1987 On meaning: Selected writings in semiotic theory. Minneapolis: University of Minnesota Press,

Greimas, Algirdas Julien 1991 Narrative semiotics and cognitive discourses. London: Pinter.

Grönhaug, Kjell, and Joyce S. Falkenberg 1998 'Success attributions within and across organizations" in Managerial and organizational cognition. Theory, methods and research. C. Eden and J-C. Spender (eds.), 93-107. London: Sage. 
Hambrick, Donald C, and Albert A. Cannella 1993 "Relative standing: A framework for understanding departures of acquired executives'. Academy of Management Journal 36: 733-762.

Haspeslagh, Philippe, and David Jemison 1991 Managing acquisitions: Creating value through corporate renewal. New York: Free Press.

Hatch, Maiy Jo 1994 'Narrative and rhetorical style in the discourses of organization theory'. Paper presented at the Academy of Management Meeting. Dallas.

Haunschild. Pamela R.. Alison Davis- Blake, and Mark Fichman 1994 'Managerial overcommitment in corporate acquisition processes'. Organization Science 5: 528-540. Heider, Fritz 1958 The psychology of interpersonal relations. New York: Wiley.

Heracleous, Loizos. and John Hendy 20(X) 'Discourse and the study of organization: Toward a structurational perspective". Human Relations 53: 1251-1285.

Hewstone, Miles 1989 Causal attribution: From cognitive processes to collective beliefs. Oxford: BlackweU.

Hirsch, Paul M. 1986 'From ambushes to golden parachutes: Corporate takeovers as an instance of cultural framing and institutional integration'. American Journal of Sociology 91: 800-837.

Hoffmann, David A., and Adam Stetzer 1998 "The role of safety climate and communication in accident interpretation: Implications for leaming from negative events'. Academy of Management Journal 41: 644-657.

Hofstede. Geert 1997 Cultures and organizations: Software of the mind. New York: McGraw-Hill.

Holstein, James A., and Jaber F. Guhrium 1997 'Active interviewing" in Qualitative research: Theory, methods and practice. David Silverman (ed.), 63-79. London: Sage.

Hunt, J. W. 1990 'Changing pattem of acquisition behavior in takeovers and tlie consequences for acquisition processes' . Strategic Management Journal 11: 69-77. 
Hyvarinen, Matti 1998 "Thick and thin narratives: Thickness of description, expectation, and causality'. Cultural Studies: A Research Volume 3: 149-174.

Jeffcutt, Paul 1994 'From interpretation to representation in organizational analysis: Postmodemism, ethnography and organizational symbolism'. Organization Studies 15/2: 241-274.

Jemison, David, and Sam Sitkin 1986 'Corporate acquisitions: A process perspective'. Academy of Management Review 11: 145-163.

Kallinikos, Jannis 1997 'Classics review science, knowledge and society: The postmodem condition revisited'. Organization 4: 113-142.

Keenoy, Tom, Cliff Oswick, and David Grant 1997 'Organizational discourses: Text and context'. Organization 4: 147-157.

Kitching, John 1967 'Why do mergers miscarry?'. Harvard Business Review 45: 84101.

Kleppestö, Stein 1993 Kultur och identitet vid foretagsuppkop och fusioner. Stockholm: , Nerenius \& Santérus. Kusewitt, John B. Jr. 1985 'An exploratory study of acquisition factors relating to performance'. Strategic Management Journal 6: 151169.

Laamanen, Tomi 1997 The acquisition of technological competencies through the acquisition of new, technology-based companies. Otaniemi, Espoo: Helsinki University of Technology.

Larsson, Elikard 1990 Coordination of action in mergers and acquisitions. Interpretive and systems approaches towards synergy. Lund: Lund University Press.

Larsson, Rikard 1993 'Barriers to acculturation in mergers and acquisitions: Strategic human resource implications'. Journal of European Business Education 2: 1-18.

Larsson, Rikard, and Sydney Finkelstein 1999 'Integrating strategic, organizations and human resource perspectives on mergers and acquisitions: A case survey of synergy realization'. Organization Science 10: 1-26. 
Leroy, Frederic, and Bemard Ramanantsoa 1997 'Cognitive and behavioural dimensions of organizational leaming in a merger: An empirical study. Jouma, of Management Studies 34: 871-894.

Levinthal, Daniel A., and James G. March 1993 'The myopia of learning'. Strategic Management Journal 14: 95-112.

Lindgren, Ulf 1982 Foreign acquisitions: Management of the integration process. Stockholm: IIB/EFI.

Lohrum, Camilla 1996 Post-acquisition integration: Towards an understanding of employee reactions. Helsinki: Swedish School of Economics and Business Administration.

Lubatkin, Michael H. 1983 'Mergers and the performance of the acquiring flrra'. Academy of Management Review 8: 218-225.

Lubatkin, Michael H. 1987 'Merger strategies and stockholder value'. Strategic Management Journal S: 39-53,

Lyotard, Jean-Francois 1979 The po.stmodem condition: A report on knowledge. Manchester: Manchester University Press.

Manning, Peter K. 1987 Semiotics and fieldwork. Newbury Park: Sage.

March, James, and J.P. Olsen 1989 Rediscovering institutions. The organizational basis of politics. New York: The Free Press.

March, James G., and Herbert A. Simon 1993 Organizations, 2nd. Ed. Oxford: Blackvé-ell

Martin, Joanne 1982 'Accounts and scripts in organizational settings' in Cognitive social psychology. A.H. Hastorf and A.M. Isen (eds.), 255-305. New York: Elsevier/North-Holland.

Martin. Joanne 1992 Cultures in organizations: Three perspectives. New York: Oxford University Press. 
Martin, Joanne, Martha Feldman, Mary Jo Hatch, and Sam Sitkin 1983 'The uniqueness paradox in organizational accounts'. Administrative Science Quarterly 28: 438-453.

Martin, Wallace 1986 Recent theories of narrative. Ithica, NY: Comell University Press.

Martinko, Mark J. 1995 Attribution theory: An organizational perspective. Delray Beach, FL: Si. Lucia Press.

Mazza, Carmelo, and Jos6 Luis Alvarez 2000 'Haute Couture and Pret-^^-Porter. The popular press and the diffusion of management practices'. Organization Studies 21/3: 567-588.

McCloskey, Donald N. 1990 If you're so smart. The narrative of economic expertise. Chicago: University of Chicago Press.

McKinlay, Alan, and Ken Starkey, editors 1998 Foucault. management and organization theory. London: Sage.

Miller, Susan, David J. Hickson, and David D. Wilson 1996 'Decision-making in organizations' in Handbook of organization studies.

S.R, Clegg, C. Hardy and W. R. Nord (eds.), 293-312. London: Sage.

Morosini, Piero, Scott Shane, and Harbir Singh 1998 "National cultural difference and cross-border acquisition performance'. Journal of Intemational Business Studies 29: 137-158.

Nahavandi, Afsaneh, and Ali R. Malekzadeh 1988 'Acculturation in mergers and acquisitions'. Academy of Management Review 13: 79-90.

Napier, Nancy K. 1989 'Mergers and acquisitions, human resource issues and outcomes: A review and suggested typology'. Journal of Management Studies 26: 271-289.

O'Connor. Ellen 1995 "Paradoxes of participation: Textual analysis and organizational change". Organization Studies 16/5: 769-803. 
O'Connor. Ellen 1996 'Telling decisions: The role of narrative in organizational decisionmaking' in Organizational decisionmaking. Z. Shapira (ed.), 304-323. New York: Cambridge University Press.

Olie, Rend 1990 'Culture and integration problems in international mergers and acquisitions'. European Management Journal : 206-2\5.

Oiie, Ren1994 'Shades of culture and institutions in international mergers". Organization Studies 15/3: 381-405.

Olie, Rene 1996 European transnational mergers. Maastricht: Proescfuift Rijskuniversiteit Limburg.

Pablo, Amy 1994 "Determinants of acquisition integration level". Academv of Management Journal 37: 803-836.

Peltonen, Tuomo 1998 'Narrative construction of expatriate experiences and career cycle: Discursive patterns in Finnish accounts of intemational career". The Intemational Journal of Human Resource Management 9/5: 875-892.

Phillips. Nelson 1995 "Telling organizational tales: On the role of narrative fiction in the study of organizations'. Organization Studies 16/4: 625-649.

Polkinghome, Donald 1987 Narrative knowing and the human sciences. Albany: State University of New York Press.

Popper, M. 1997 The glorious failure. Journal of Applied Behavioral Science 33: 2745.

Porter, Michael E. 1987 'From competitive advantage to corporate strategy'. Harvard Business Review May-june: 43-59.

Powell, Walter W., and Paul J. DiMaggio 1991 The new institutionalism in organizational analysis. Chicago: University of Chicago Press.

Propp, Vladimir 1968 Morphology of the folktale. Austin, TX: University of Texas Press. 
Rappaport. Julian 1993 'Narrative studies. Personal accounts, and identity transformation in the mutual help context'. Journal of Applied Behavioral Science 29: 239-256.

Risberg. Anette 1998 Ambiguities thereafter: An interpretive approach to acquisitions. Lund: •' Lund University Press,

Roe. Emery 1994 Narrative policy analysis: Theory and practice. Durham, NC: Duke University Press.

Sahlin-Andersson, Kerstin 1996 'Imitating by editing success' in Translating organizational change.

Barbara Czamiawska and Guje Sev6n (eds.), 69-92. Berlin: Walter de Gruyter. Salancik, Gerald R,. and James R. Meindl 1984 'Corporate attributions as strategic illusions of management control'. Administrative Science Quarterly 29: 238-254.

Sales. Amy L., and Philip H. Mirvis 1984 'When cultures collide: Issues in acquisitions' in New futures: The challenge of managing corporate transitions. J. Kimberley and R, Quinn (ed.s.). 107-133. Homewood: Dow Jones-Irvin.

Schneider, Susan C, and Roger L. M. Dunbar 1992 'A psychoanalytic reading of hostile takeover events'. Academy of Management Review 17: 337-567.

Schweiger, David. M, and Angelo S. DeNisi 1991 'Communication with employees following a merger: A longitudinal field experiment'. Academy of Management Journal 34: 100-137.

Schweiger, David M., John M. Ivancevich. and Frank R. Power 1987 'Executive action for managing human resources before and after acquisition'. Academy of Management Executive 1: 127-138.

Seth, Anju 1990 'Value creation in acquisitions: A re-examination of performance issues'. Strategic Management Journal 11:99-115.

Shrivastava, Patjl 1986 'Postmerger integration'. Journal of Business Strategy 7: 65-76. 
Silverman, David 1993 Interpreting qualitative data: Methods for analyzing talk, text and interaction. London: Sage.

Skoldberg, Kaj 1994 'Tales of change: Public administration reform and narrative mode'. Organization Science 5: 219-238.

Staw. Barry M., Pamela 1. McKechnie, and Sheila M. Puffer 1983 'The justification of organizational performance'. Administrative Science Quarterly 28: 582-600.

Taylor, Shelley E. 1989 Positive illusions. Creative selfdeception and the healthy mind. New York: Basic Books.

Tienari, Janne, Eero Vaara, and Katja Kaihua 1999 'Talouden diskurssien uusintamisen jaljilla — Eli miten yritysjarjestelya kasitellaan suomalaisessa lehdistossa'. Hatlinnon tutkimus 18: 232- 250.

Vaara, Eero 1999 'Cultural differences and postmerger problems: Misconceptions and cognitive simplifications'. Nordiske Organisasjonsstudier 1: 59-88.

Vaara, Eero 2000 'Constructions of cultural differences in post-merger change processes: A sensemaking perspective on Finnish-Swedish cases'. Management 3: 81110.

Vaara, Eero 2002 'Role-bound actors in corporate combinations: A sociopolitical perspective on f)ost-merger change processes'. Scandinavian Jottmat of Management, forthcoming.

Van Maanen, John 1988 Tales of the field. On writing ethnography. Chicago: University of Chicago Press.

Very, Philippe, Roland Calori, and Michael Lubatidn 1993 'An investigation of national and organizational cultural influences on recent European mergers' in Advances in .strategic management.

P. Shrivastava, A. Huff, and J. Dutton (eds), 323-347. London: JAI Press. 
Very. Philippe. Michael Lubatkin. Roland Calori, and John Veiga 1997 'Relative standing and the performance of recently acquired European firms'. Strategic Management Journal 18: 593-614.

Villinger. Roland 1996 'Post-acquisition managerial leaming in Central East Europe'. Organization Studies 72: 181-206.

Wagner, J. A. HI, and Richard Z. Gooding 1997 "Equivocal information and attribution: An investigation of pattems of managerial sensemaking". Strategic Management Joumal 18: 275-286.

Walter. Gordon. A. 1985 'Culture collisions in mergers and acquisitions' in Organizational culture. P. Frost, G. Moore, M. Reis Louis. C. Lundberg and J. Martin (eds.). 301-314. Beverly Hills: Sage.

Watson, Tony J. 2000 "Ethnographic fiction science: Making sense of managerial work and organizational research processes with Caroline and Terry'. Organization 7: 489-510.

Weber. Yaakov. and D. M. Schweiger 1992 'Top management culture conflict in mergers and acquisitions". The International Joumal of Conflict Management 3: 1-17.

Weber, Yaakov, Oded Shenkar, and Adi Raveh 1996 'National and corporate cultural fit in mergers/acquisitions: An exploratory study". Management Science 42: 1215 1227.

Weick, Karl 1995 Sensemaking in organizations. Thousand Oaks: Sage.

Weiner, Bemard 1986 An attribution theory of achievement motivation and emotion. New York: Springer Verlag.

Westley, Frances R. 1990 'Middle managers and strategy: Microdynamics of inclusion". Strategic Management Joumal 11: 337- 351.

White, Hayden 1987 The content of the form. Narrative discourse and historical representation.

Baltimore. MR: John Hopkins University Press. 
Williamson, Oliver E. 1996 The mechanisms of governance: New York: Oxford University Press 